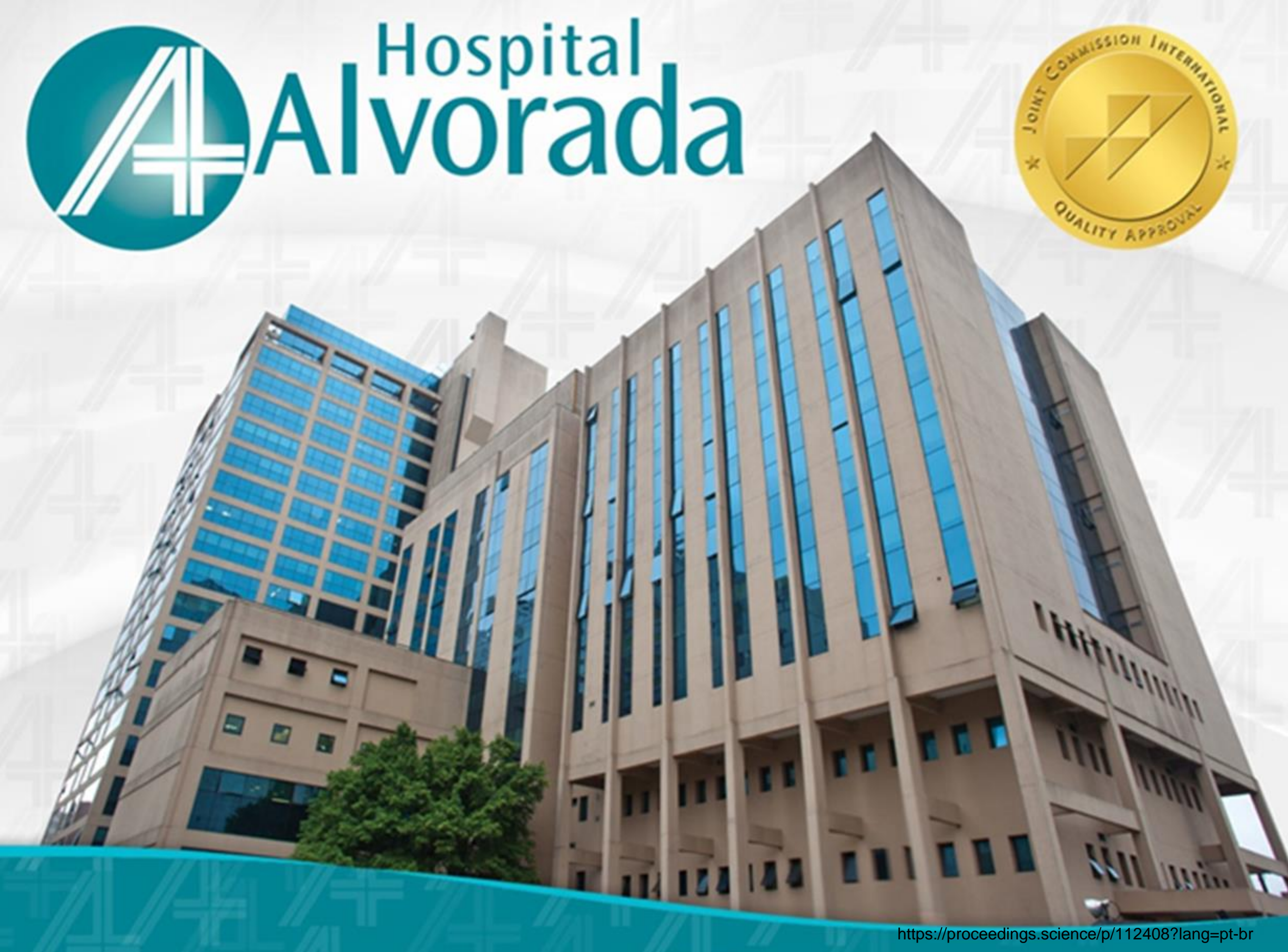




\section{Impacto de ações multimodais na redução das infecções relacionadas ao acesso venoso central em Unidade de Terapia Intensiva de adultos em um hospital privado do município de São Paulo}




\section{Área Geral}

Apartamentos

Leitos de enfermaria

UTI Adulto

Unidade Semi Crítica

$$
\text { UTI Pediátrica }
$$

Salas Cirúrgicas

Leitos
$25.835 \mathrm{~m}^{2}$

105

30

20

10

10

11

175 


\section{Aumento das IPCS-CVC (2017-2018)}

Necessidade de um plano de ação mais robusto e sustentável

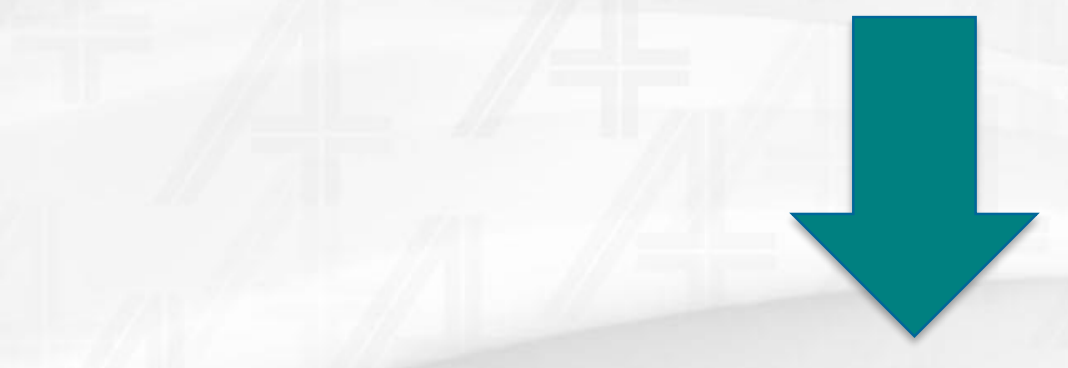




\section{Introdução}

\section{Infecção da corrente sanguínea - CVC:}

- Elevada prevalência

- Elevada morbiletalidade

- Aumento do tempo de internação

- Multifatorial

- Marcador de qualidade assistencial 


\section{Material e Método}

\section{Elaboração de múltiplas medidas de prevenção:}

- Auditoria diagnóstica (inserção e manutenção)

- Envolvimento dos PAS - UTI adulto (gestores, equipe assistencial e SCIH)

- Plano de ação baseado nos achados de auditoria (envolvimento - PAS)

- Auditorias de seguimento contínuas

- Divulgação dos resultados aos PAS

PASSOS PARA MANIPULAÇÃO DOS CATETERES VENOSOS CENTRAIS
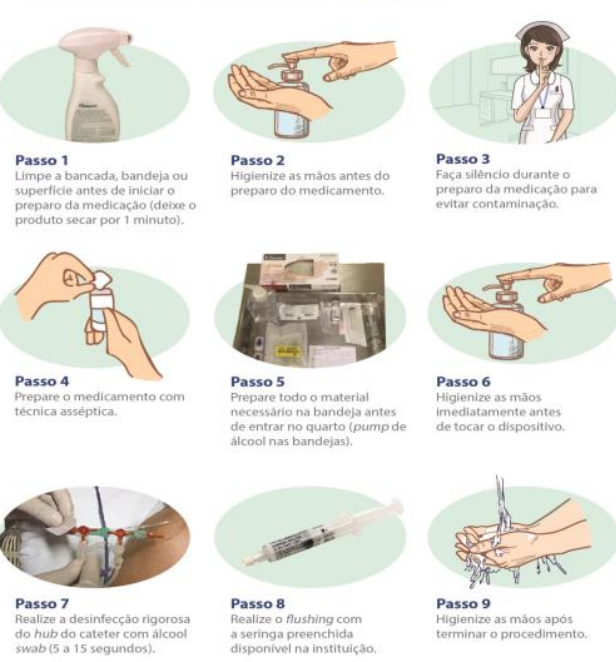


\section{Material e Método}

- Implantação de novas tecnologias e capacitação:

- Curativo com $\mathrm{CHG}$

- Seringa preenchida com solução salina

- Padronização do dispositivo valvulado para cateteres centrais

- Orientação e acompanhamento da equipe
médica (indicação, inserção e manutenção de

- Orientação e acompanhamento da equipe
médica (indicação, inserção e manutenção de CVC)

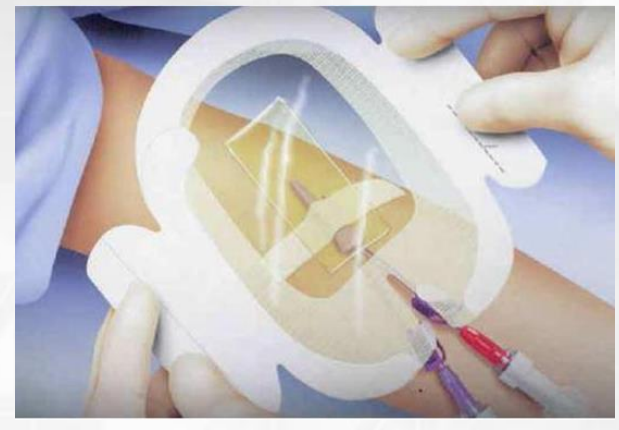




\section{Material e Método}

Redimensionamento da equipe de enfermagem

- Escala de enfermagem fixa com rodízio a cada 7 dias

- Avaliação do consumo de álcool gel por profissional de enfermagem

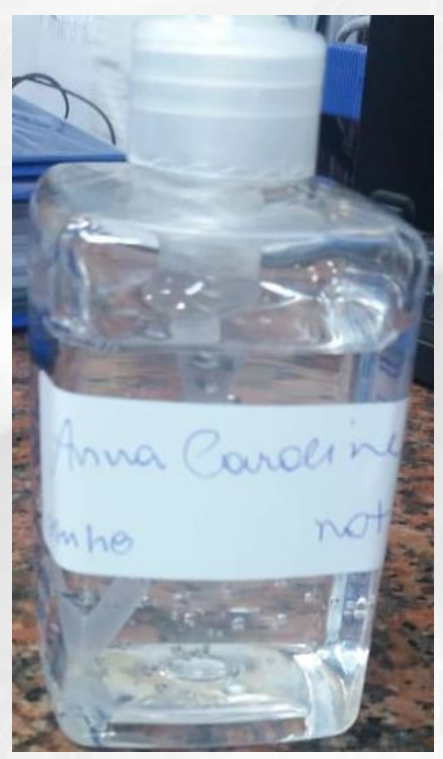

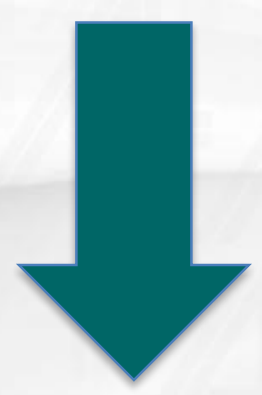

个 $56 \%$ consumo de solução alcóolica

\section{Responsabilização}




\section{Consumo de álcool gel na UTI Adulto 2018 (ml/paciente-dia)}

160,0 140,0 120,0 100,0 80,0 60,0 40,0 20,0 0,0
148,0

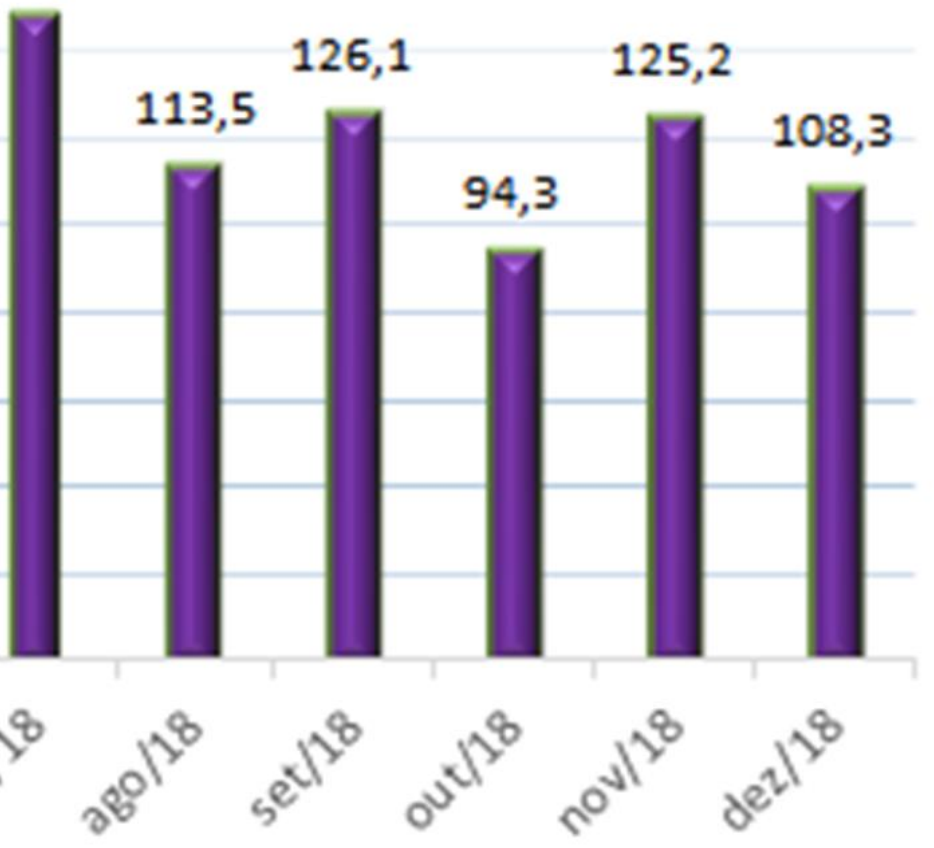




\section{Material e Método}

\section{Envolvimento dos PAS}

Estação de simulação realística de Higiene das mãos e Terapia infusional

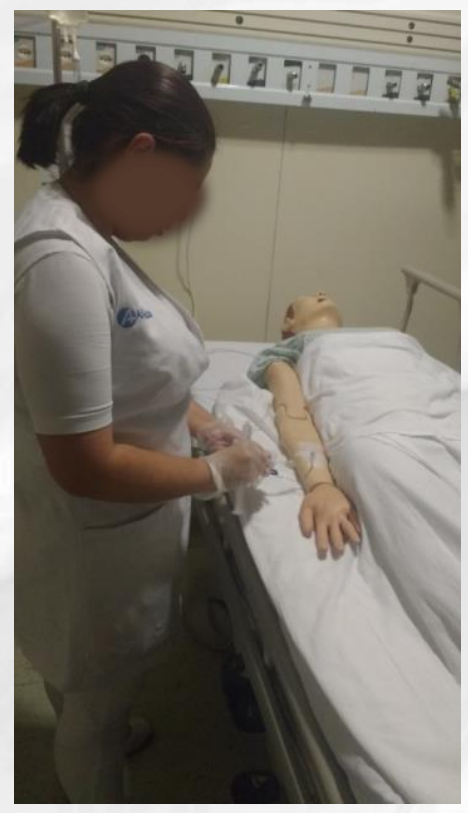

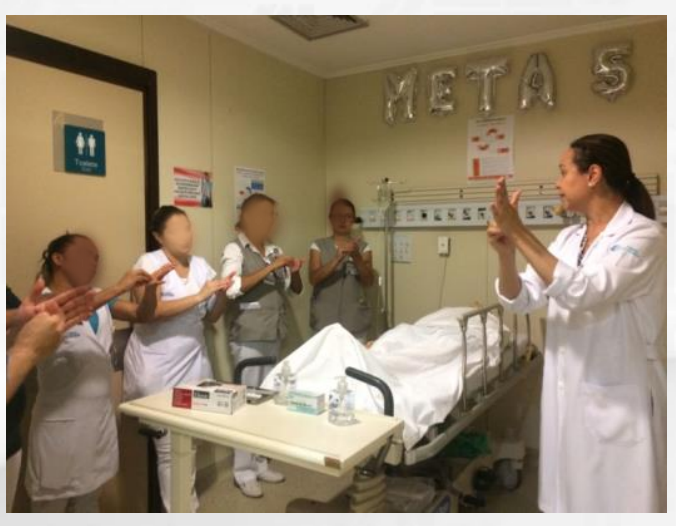

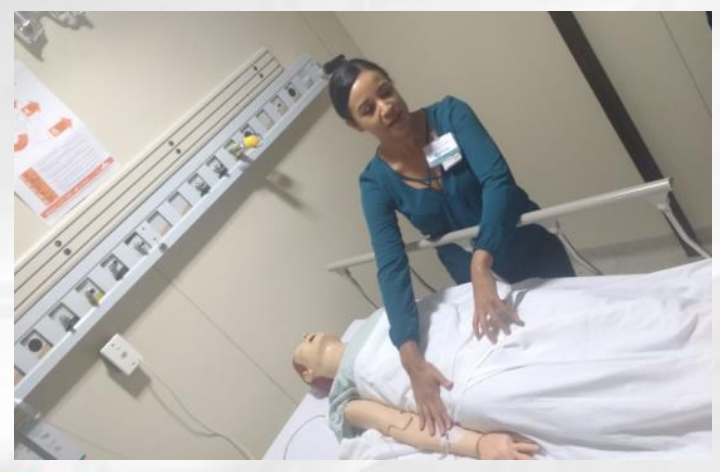

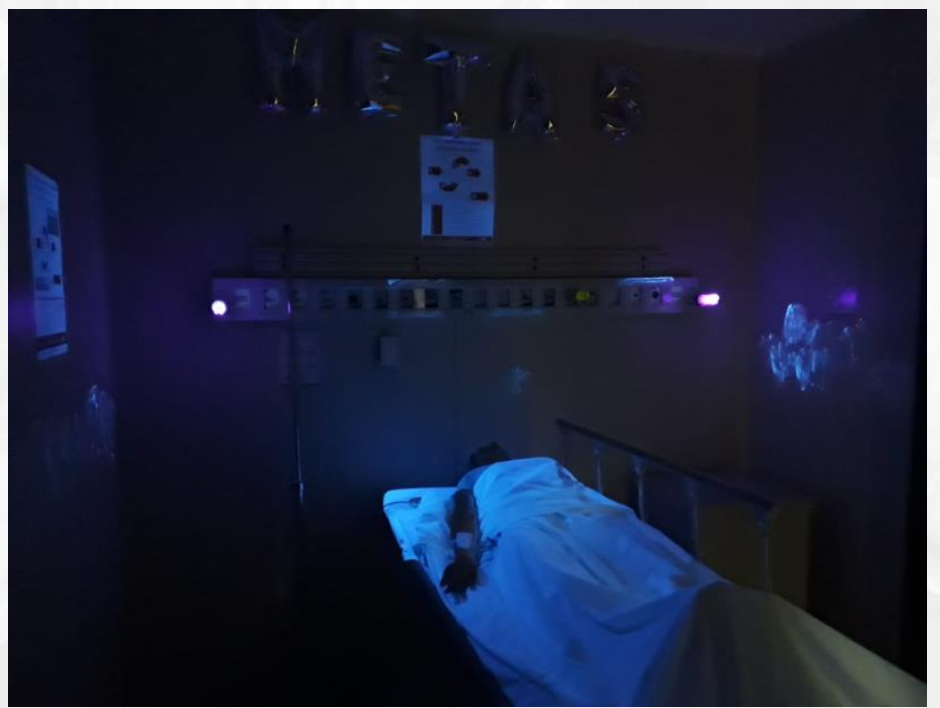

A-Alvoriada 


\section{1 \\ Material e Método}

Workshop de Terapia Infusional e Higiene das Mãos
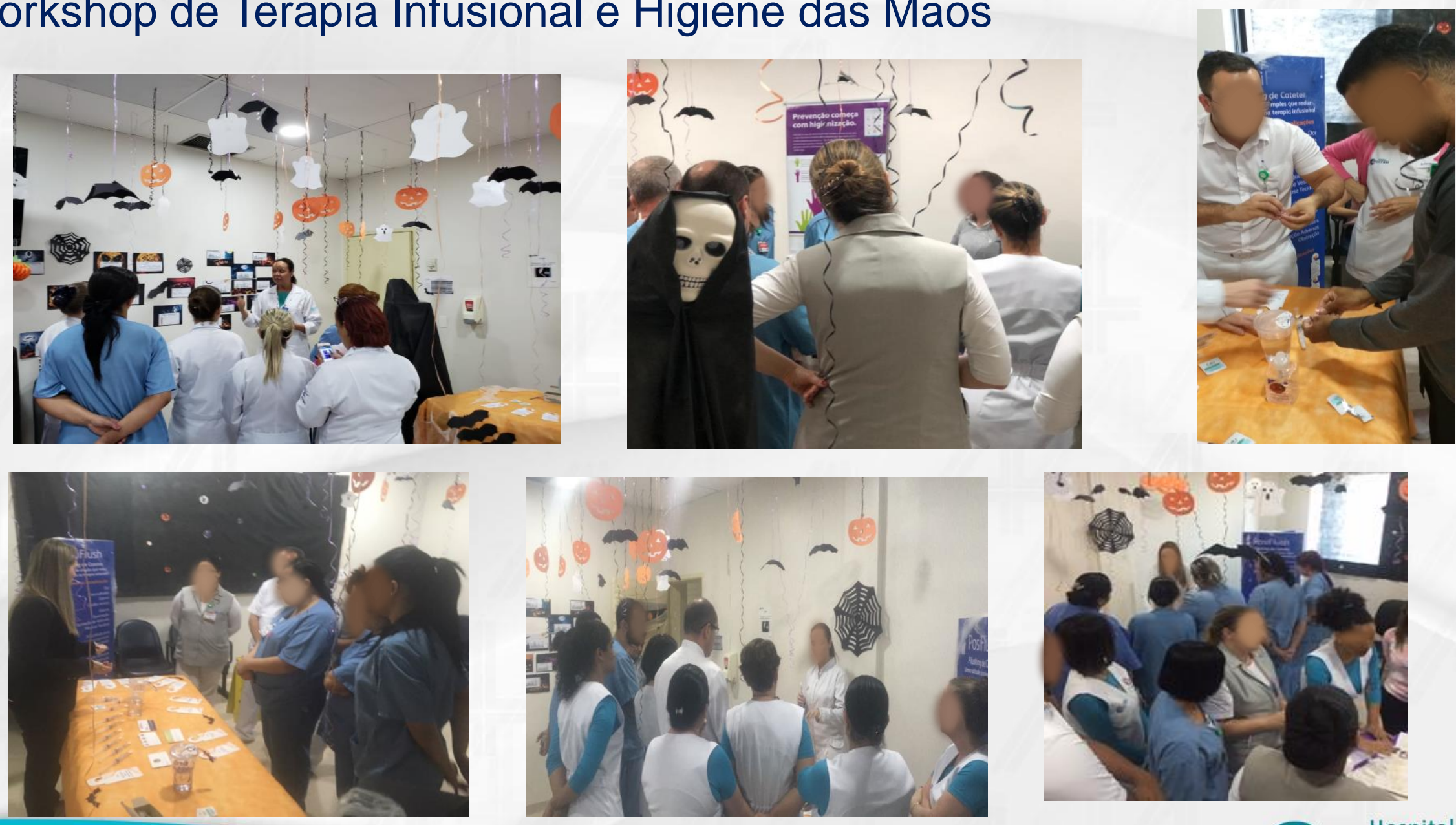

A-Alvorada 


\section{Resultados}

\section{Redução significativa das IPCS-CVC no $2^{\circ}$ semestre 2018}

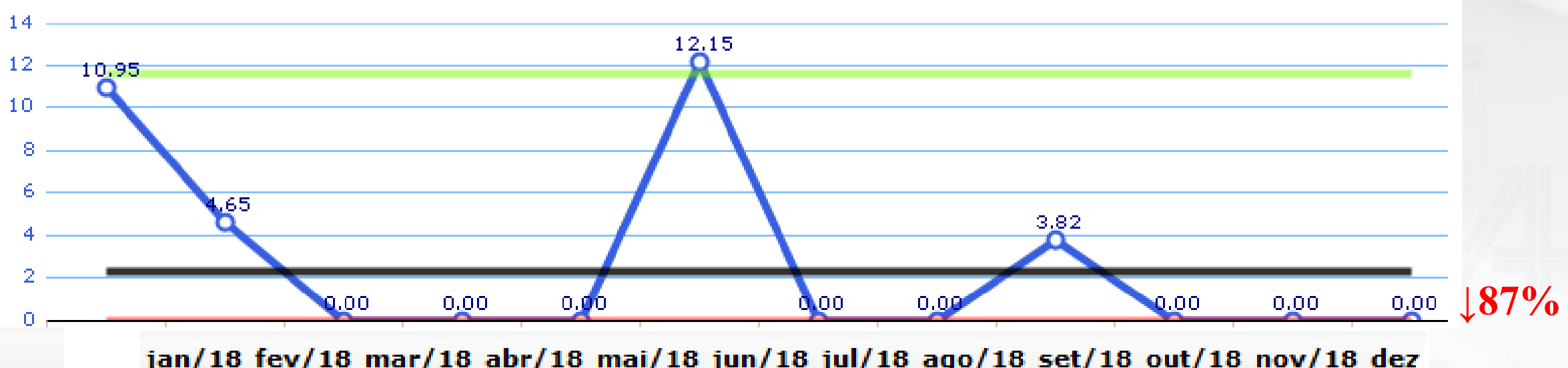

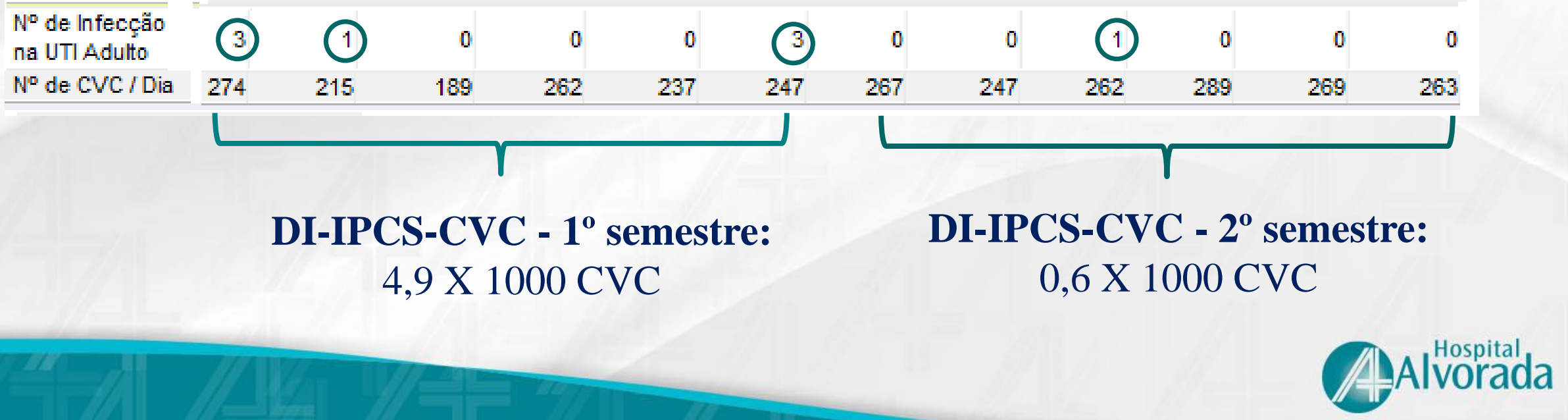


1. A prevenção das IPCS-CVC é possível com estratégias assistenciais estruturadas e contínuas baseadas nas necessidades de cada instituição

2. A educação continuada, a valorização das lideranças e 0 envolvimento dos PAS são fatores fundamentais para a redução sustentada destas infecções no ambiente hospitalar. 


\section{Obrigada}

revetria.cardoso@hospitalalvorada.com.br 